\title{
Aspirin use is associated with a reduced risk of cholangiocarcinoma: a systematic review and meta-analysis
}

This article was published in the following Dove Press journal: Cancer Management and Research

\author{
Jianping Xiong* \\ Weiyu $\mathrm{Xu}^{*}$ \\ Jin Bian \\ Hanchun Huang \\ Yi Bai \\ Yiyao Xu \\ Xin Lu \\ Haitao Zhao
}

Department of Liver Surgery, Peking Union Medical College Hospital, Chinese Academy of Medical Sciences and Peking Union Medical College (CAMS \& PUMC), Beijing, 100730 , China

*These authors contributed equally to this work
Correspondence: Xin Lu; Haitao Zhao Department of Liver Surgery, Peking Union Medical College Hospital, Chinese Academy of Medical Sciences and Peking Union Medical College (CAMS \& PUMC), No. 9, Dongdan Santiao, Dongcheng District, Beijing, 100730, China

Tel +861069156042

Fax +86 I06 9156043

Email luxinln@163.com; zhaoht@pumch. cn
Background: Aspirin has been revealed to probably decrease the risk of cholangiocarcinoma (CCC), which, nevertheless, is of controversy. To this end, a systematic review and meta-analysis was performed to investigate the above-described association.

Methods: We thoroughly searched PubMed, EMBASE, and ISI Web of Science for relevant studies published prior to October 2017, followed by random-effects model for calculation of pooled ORs and corresponding 95\% CIs. Additionally, subgroup and sensitivity analyses were carried out to confirm whether the outcomes were stable.

Results: Nine articles, consisting of 12,535 CCC patients and 92,97,450 healthy controls, were enrolled in this study. We demonstrated a significantly decreased risk of CCC in those using aspirin, with studies being heterogeneous ( $\mathrm{OR}=0.69$; $\left.\mathrm{CI}=0.43-0.94 ; I^{2}=97.4 \%\right)$. Moreover, this relationship was detected only in case-control studies $(\mathrm{OR}=0.65 ; 95 \% \mathrm{CI}=0.38-0.93)$, rather than cohort studies $(\mathrm{OR}=0.94 ; 95 \% \mathrm{CI}=0.70-1.27)$. Besides, in separated analysis of intrahepatic CCC and extrahepatic CCC, aspirin was more strongly correlated with a declined risk of intrahepatic $\mathrm{CCC}\left(\mathrm{OR}=0.33,95 \% \mathrm{CI}=0.26-0.39 ; l^{2}=93.6 \%\right)$ than the risk of extrahepatic $\mathrm{CCC}$ $\left(\mathrm{OR}=0.56,95 \% \mathrm{CI}=0.41-0.73 ; I^{2}=0 \%\right)$.

Conclusion: Collectively, the aspirin administration was correlated with a significant $31 \%$ decreased risk of CCC, particularly in the intrahepatic CCC.

Keywords: aspirin, cholangiocarcinoma, biliary tract neoplasms, meta-analysis

\section{Introduction}

Cholangiocarcinoma (CCC) is a type of malignancy derived from the bile duct epithelium, which was first described by Durand-Fardel in 1840. ${ }^{1}$ These tumors can be categorized into intrahepatic (ICC), extrahepatic(ECC), and hilar cholangiocarcinoma according to tumor location. ${ }^{2} \mathrm{Hilar}$ cholangiocarcinoma is usually considered as ECC. ${ }^{3}$ CCC ranks the second among all primary hepatic carcinoma (HCC) in terms of incidence, accounting for $10 \%-25 \%$ of malignant HCCs and 3\% of all gastrointestinal neoplasms. ${ }^{4,5}$ In addition, the incidence of CCC has continued to increase in recent years. Interestingly, there are certain differences of the epidemiological features between ICC and ECC. To be specific, there has been an increased incidence of ICC, while a decreased incidence of ECC in certain countries, including the UK and the USA. ${ }^{6}$ In the USA, the age-adjusted incidence rate of ICC has risen by $165 \%$ in the last two decades, whereas that of ECC has declined by $14 \% .^{7}$ In addition, CCC patients harbor a particularly poor prognosis. The overall 1-, 3-, and 5-year relative survival rates have been demonstrated to be $25.0 \%, 9.7 \%$, and $6.8 \%$, respectively, nearly without any changes in recent decades. ${ }^{8}$ The causes of CCC are still not well defined, with only several 
risk factors being identified, including parasitic infections, bile duct cysts, hepatolithiasis as well as primary sclerosing cholangitis. ${ }^{9}$ Recent studies have reported that some factors may increase CCC risk, including cirrhosis, hepatitis B or C, diabetes mellitus, gallstones, alcohol, and smoking. ${ }^{10-15}$ These risk factors have a common feature, which may be involved in the pathogenesis of CCC through a chronic biliary tract inflammatory process. Bile duct inflammation is a recognized cause of duct carcinogenesis. ${ }^{11}$ Recently, a certain study has reported that aspirin, an inhibitor of COX-2, might suppress cancer progression by suppressing inflammatory processes. ${ }^{16}$ Moreover, aspirin has been demonstrated to probably decrease CCC risk. Nevertheless, the results are conflicting. Accordingly, this meta-analysis was conducted for a better evaluation of the relationship between aspirin use and CCC risk.

\section{Methods}

The present research was carried out in line with PRISMA Statement ${ }^{17}$ and the guidelines for Meta-analysis Of Observational Studies in Epidemiology (MOOSE). ${ }^{18}$

\section{Data sources and search strategy}

PubMed, EMBASE, and Web of Science databases were thoroughly searched for relevant published studies using the following keywords: ("aspirin" OR "non-steroidal antiinflammatory drugs" OR "NSAIDs" OR "salicylate" OR "cyclooxygenase-2 inhibitors" OR "COX-2 inhibitors") and ("biliary tract neoplasms" OR "cholangiocarcinoma" OR "bile duct cancer" OR "biliary tract cancer"). Neither language nor date of publication was restricted.

\section{Inclusion criteria}

Eligible studies were included if they met the following criteria: study design (case control or cohort); aspirin as the exposure factor and CCC or bile duct cancer or biliary tract cancer as the outcome; accessible OR/risk ratio (RR) values and corresponding $95 \%$ CIs or adequate data for calculation. In the case of the same data reported by two studies, the study with a larger sample was selected.

\section{Data extraction and quality evaluation}

The extraction of necessary data was independently conducted by two investigators (WX and JB) from the selected studies following standardized protocol. The following data were extracted from every article: name of first author, year of publication, country, study design (case-control or cohort), period of follow-up, number of subjects, adjusted confounding variables, sources of controls, and OR/RR values and 95\% CIs.
The study quality was assessed by the Newcastle-Ottawa Scale (NOS), ${ }^{19}$ and quality categories were assigned in line with the scores of every research. The maximal score was 9 points. To be specific, NOS scores of $<4,4-6$, and 7-9 suggested low-, medium-, and high-quality studies, respectively. ${ }^{20}$ All discrepancies were handled by consensus.

\section{Statistical analysis}

The association between $\mathrm{CCC}$ risk and aspirin use was assessed by OR/RR values and corresponding 95\% CIs, followed by quantification by random-effects model, which was proposed by DerSimonian and Laird. ${ }^{21}$ HRs were considered as equivalent to RRs.

The $I^{2}$ statistic was employed for quantification of heterogeneity between studies, where $I^{2}$ values of $25 \%, 50 \%$, and $75 \%$ indicated low, medium, and high heterogeneity, respectively. ${ }^{22}$ A $P$-value $<0.1$ implicated the presence of heterogeneity. Meta-regression was used to evaluate the extent to which heterogeneity between the results was related to study design, geographical locations, and confounders adjusted for smoking status, alcohol use, and cholangitis. Funnel plots and Begg's ${ }^{23}$ and Egger's ${ }^{24}$ tests were employed to assess publication bias, where a $P$-value $<0.05$ or funnel plot asymmetry was indicative of bias. ${ }^{25}$

Subgroup analyses were further conducted according to study design, geographic regions, tumor subtype, and whether smoking, alcohol consumption, or cholangitis were adjusted. Moreover, the stability of the outcomes was assessed by sensitivity analysis via sequential omission of one by one, which was conducted by altering the pooling model (fixed-effects model or random-effects model) and eliminating researches with NOS sources under 7 as well. ${ }^{26}$

STATA version 12.0 (Stata) was employed for statistical analysis.

\section{Results \\ Study selection and study features}

The selection process is shown in Figure 1. In total, 605 studies were initially selected (118, 276, and 211 from PubMed, EMBASE, and Web of Science, respectively), while, 189 researches were repeated. Another 338 researches were eliminated after reviewing title and abstract. After further elimination of another five studies in consideration of inadequate information, ${ }^{27-31}$ nine eligible observational researches were ultimately enrolled in this meta-analysis. ${ }^{32-40}$

The major features of nine enrolled researches are summarized in Table $1 .{ }^{32-40}$ Among them, four, three, and two studies were conducted in the USA, the UK, and China, 


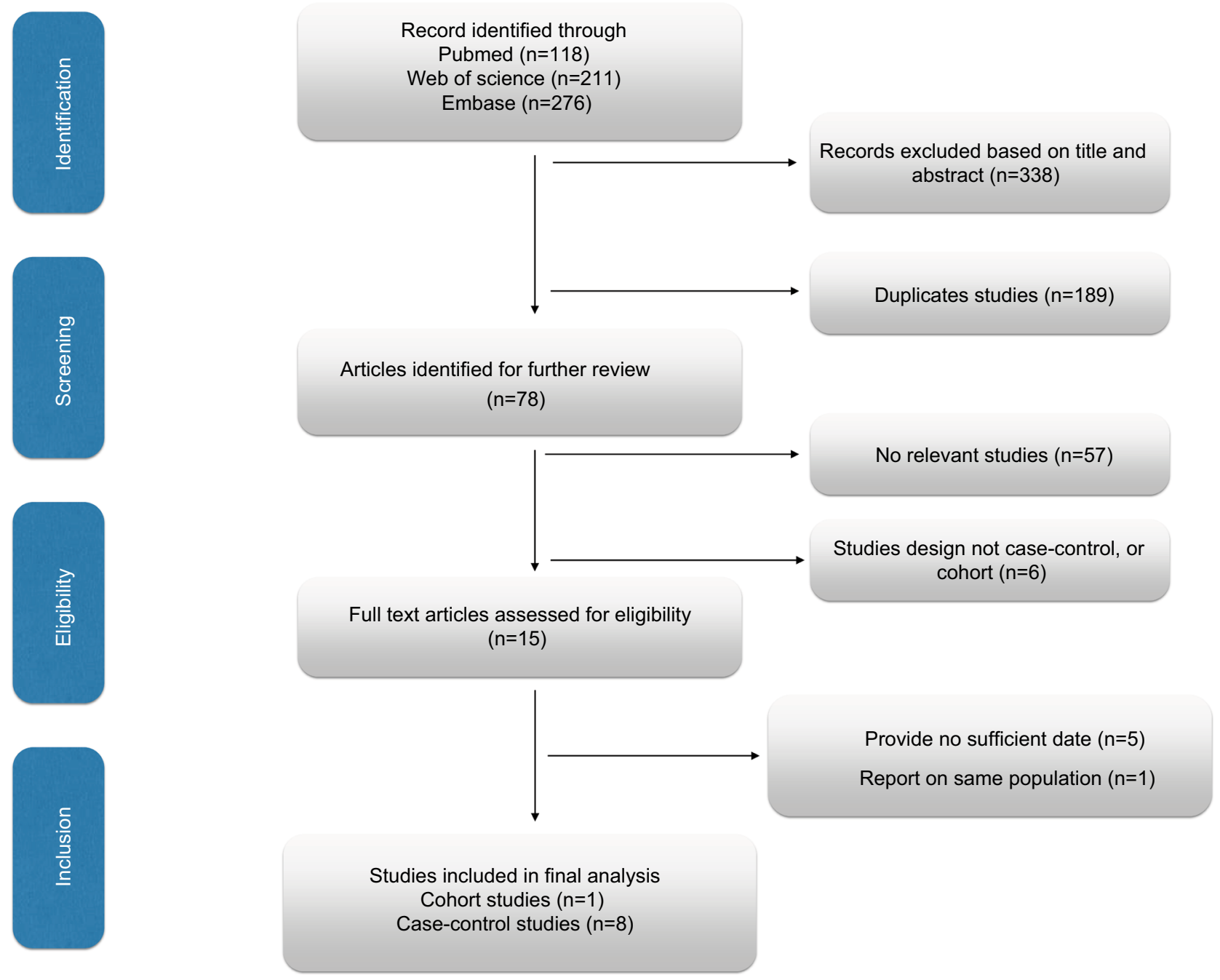

Figure I The process of study selection for the meta-analysis.

respectively, all of which, were observational ones. Eight of these studies were case-control design, while the remaining one was cohort design. A total of 12,535 CCC subjects and $92,97,450$ healthy controls were included to examine the role of aspirin on CCC risk in this meta-analysis, ranging from 1977 to 2016. The NOS scores of all selected researches varied from 5 to 9 , with seven high-quality researches and two of medium quality (Table 2).

\section{Overall results}

Of the nine researches, a significantly lower CCC risk was observed in those taking aspirin in three studies, while in the remaining six studies, there was no such correlation between the two. The pooled estimate was significant $(\mathrm{OR}=0.69 ; 95 \%$ $\mathrm{CI}=0.43-0.94)$, with studies being significantly heterogeneous $(I=97.4 \% ; P=0.001$; Figure 2$)$. Compared with non- use, aspirin administration was correlated with a significant $31 \%$ declined CCC risk. Nevertheless, the above correlation was detected only in case-control studies $(\mathrm{OR}=0.65 ; 95 \%$ $\mathrm{CI}=0.38-0.93)$, but not in cohort studies $(\mathrm{OR}=0.94 ; 95 \%$ $\mathrm{CI}=0.70-1.27$; Table 3 ).

\section{Subgroup and sensitivity analyses}

The outcomes of subgroup and sensitivity analyses are displayed in Table 3. In the separated analyses of ICC and ECC, we found that aspirin was more strongly correlated with a declined risk of ICC $(\mathrm{OR}=0.33 ; 95 \% \mathrm{CI}=0.26-0.39$; $\left.I^{2}=93.6 \%\right)$ than that of ECC $(\mathrm{OR}=0.56 ; 95 \% \mathrm{CI}=0.41-0.73$; $P^{2}=0 \%$ ). Sensitivity analysis indicated that after elimination of studies with NOS sources $<7$, aspirin use was stably related to CCC risk (Table 3). Moreover, the overall outcomes of the correlation between aspirin and $\mathrm{CCC}$ were stable in changing 
Table I The main characteristics of the included studies

\begin{tabular}{|c|c|c|c|c|c|c|c|c|}
\hline $\begin{array}{l}\text { Studyl } \\
\text { Years of } \\
\text { publication }\end{array}$ & Country & $\begin{array}{l}\text { No. casel } \\
\text { person-years }\end{array}$ & $\begin{array}{l}\text { Follow- } \\
\text { up }\end{array}$ & $\begin{array}{l}\text { Sources } \\
\text { of } \\
\text { controls }\end{array}$ & $\begin{array}{l}\text { Subtype } \\
\text { of } \\
\text { cancer }\end{array}$ & $\begin{array}{l}\text { Study } \\
\text { design }\end{array}$ & Adjusted factors & $\begin{array}{l}\text { Adjusted } \\
\text { OR/RR } \\
(95 \% \mathrm{CI})\end{array}$ \\
\hline $\begin{array}{l}\text { Choi et al } \\
2016^{34}\end{array}$ & USA & $2,395 / 4,679$ & $\begin{array}{l}2000 \\
2014\end{array}$ & Hospital & $\begin{array}{l}\text { ICC } \\
\text { ECC }\end{array}$ & $\begin{array}{l}\text { Case- } \\
\text { control }\end{array}$ & $\begin{array}{l}\text { Age, sex, race, obesity, } \\
\text { hypertension, diabetes, CVA, } \\
\text { coronary artery disease, } \\
\text { peripheral vascular disease, } \\
\text { atrial fibrillation, nonalcoholic } \\
\text { fatty liver disease/nonalcoholic } \\
\text { steatohepatitis, PSC, cirrhosis, } \\
\text { IBD, and smoking status }\end{array}$ & $\begin{array}{l}\text { ICC : } 0.35 \\
(0.29,0.42) \\
\text { ECC: } 0.32 \\
(0.27,0.40)\end{array}$ \\
\hline $\begin{array}{l}\text { Petrick et al } \\
2015^{39}\end{array}$ & USA & $200 / I,|7,20,56|$ & $\begin{array}{l}2001- \\
2013\end{array}$ & Population & ICC & Cohort & $\begin{array}{l}\text { Sex, age (continuous), race } \\
\text { (white, black, Asian/Pacific } \\
\text { Islander, American Indian/ } \\
\text { Alaskan Native, other), } \\
\text { cohort (AARP, AHS, USRT, } \\
\text { PLCO, HPFS, CPSII, IWHS, } \\
\text { BWHS, WHI, NHS), BMI } \\
\text { (continuous), smoking status } \\
\text { (nonsmoker, former smoker, } \\
\text { current smoker), alcohol }\end{array}$ & $\begin{array}{l}0.94(0.70, \\
\text { I. } 27)\end{array}$ \\
\hline $\begin{array}{l}\text { Liu et al } \\
2005^{36}\end{array}$ & China & $191 / 959$ & $\begin{array}{l}1997- \\
2001\end{array}$ & Population & ECC & $\begin{array}{l}\text { Case- } \\
\text { control }\end{array}$ & $\begin{array}{l}\text { Age, sex, education, and } \\
\text { biliary stone status }\end{array}$ & $\begin{array}{l}0.48(0.19 \\
1.19)\end{array}$ \\
\hline $\begin{array}{l}\text { Burr et al } \\
2014^{33}\end{array}$ & UK & $81 / 275$ & $\begin{array}{l}2004- \\
2010\end{array}$ & Population & $\mathrm{CCC}$ & $\begin{array}{l}\text { Case- } \\
\text { control }\end{array}$ & $\begin{array}{l}\text { Age at diagnosis and gender, } \\
\text { smoking and type2 diabetes }\end{array}$ & $\begin{array}{l}0.45(0.22 \\
0.92)\end{array}$ \\
\hline $\begin{array}{l}\text { Grainge et al } \\
2009^{35}\end{array}$ & UK & $286 / 3,913$ & $\begin{array}{l}1987- \\
2002\end{array}$ & Population & $\mathrm{CCC}$ & $\begin{array}{l}\text { Case- } \\
\text { control }\end{array}$ & $\begin{array}{l}\text { Cigarette smoking, alcohol } \\
\text { consumption, and BMI }\end{array}$ & $\begin{array}{l}1.00(0.80 \\
1.26)\end{array}$ \\
\hline $\begin{array}{l}\text { Coogan et al } \\
2000^{40}\end{array}$ & USA & $125 / 5,952$ & $\begin{array}{l}1977- \\
1998\end{array}$ & Hospital & ECC & $\begin{array}{l}\text { Case- } \\
\text { control }\end{array}$ & $\begin{array}{l}\text { Age, sex, interview year, } \\
\text { center, race, religion, } \\
\text { cigarettes, family history of } \\
\text { digestive cancer, education, } \\
\text { and alcohol consumption }\end{array}$ & $\begin{array}{l}0.5(0.3 \mathrm{I}, \\
\mathrm{I} . \mathrm{I})\end{array}$ \\
\hline $\begin{array}{l}\text { Peng et al } \\
2015^{37}\end{array}$ & China & $720 / 840$ & $\begin{array}{l}2002- \\
2011\end{array}$ & Population & $\mathrm{CCC}$ & $\begin{array}{l}\text { Case- } \\
\text { control }\end{array}$ & NR & $\begin{array}{l}1.13(0.45 \\
1.67)\end{array}$ \\
\hline $\begin{array}{l}\text { Altaii et al } \\
2017^{38}\end{array}$ & USA & $8,460 / 81,08,530$ & $\begin{array}{l}1999- \\
2016\end{array}$ & Hospital & $\mathrm{CCC}$ & $\begin{array}{l}\text { Case- } \\
\text { control }\end{array}$ & $\begin{array}{l}\text { Age, gender, ethnicity, } \\
\text { primary sclerosing cholangitis, } \\
\text { inflammatory bowel disease, } \\
\text { cirrhosis, smoking }\end{array}$ & $\begin{array}{l}0.86(0.82, \\
0.90)\end{array}$ \\
\hline $\begin{array}{l}\text { Talboys et } \\
\text { al } 20 \mathrm{I}^{32}\end{array}$ & UK & $77 / 251$ & $\begin{array}{l}2004- \\
2010\end{array}$ & Population & $\mathrm{CCC}$ & $\begin{array}{l}\text { Case- } \\
\text { control }\end{array}$ & Age and gender & $\begin{array}{l}0.55(0.28 \\
1.07)\end{array}$ \\
\hline
\end{tabular}

Abbreviations: AAPR, American Association of Retired Persons; AHS, Agriculture Health Study; BCDDP, The Breast Cancer Detection Demonstration Project; BMI, body mass index; BWHS, Black Women's Health Study; CCC, cholangiocarcinoma; CPSII, Cancer Prevention Study II; CVA, cerebrovascular accident; ECC, extrahepatic cholangiocarcinoma; HPFS, Health Professionals Follow-up Study; IBD, inflammatory bowel disease; ICC, intrahepatic cholangiocarcinoma; NHS, Nurses' Health Study; NR, none reported; PLCO, Prostate, Lung, Colorectal and Ovarian Cancer Screening Trial; PSC, primary sclerosing cholangitis; RR, relative risk; WHI, Women's Health Initiative; USRT, United State Radiologic Technologist Study.

the pooling model (fixed-effects model: $\mathrm{OR}=0.64 ; 95 \%$ $\mathrm{CI}=0.61-0.67$ and random-effects model: $\mathrm{OR}=0.69 ; 95 \%$ $\mathrm{CI}=0.43-0.94$; Table 3). In sequential omission of research one by one for evaluation of the outcomes stability, the pooled risk estimate was not affected by any study (Figure 3). Meta-regression analyses were also performed to examine the potential source of heterogeneity, which, however, did not indicate that the study design $(P=0.980)$, geographical locations $(P=0.965)$, or confounders adjusted for smoking status $(P=0.914)$, alcohol use $(P=0.759)$, or cholangitis $(P=0.745)$ was a source of heterogeneity.

\section{Publication bias}

The funnel plot failed to demonstrate any substantial asymmetry, neither did Begg's $(P=0.468)$ nor Egger's tests reveal any substantial publication bias $(P>0.05$; Figure 4$)$.

\section{Discussion}

Aspirin has been widely applied in prevention and treatment of diverse cerebrovascular disorders, such as myocardial infarction and stroke. At present, great attention has been paid to other potential benefits of aspirin globally. For instance, aspirin has been suggested to reduce the risk of certain types 


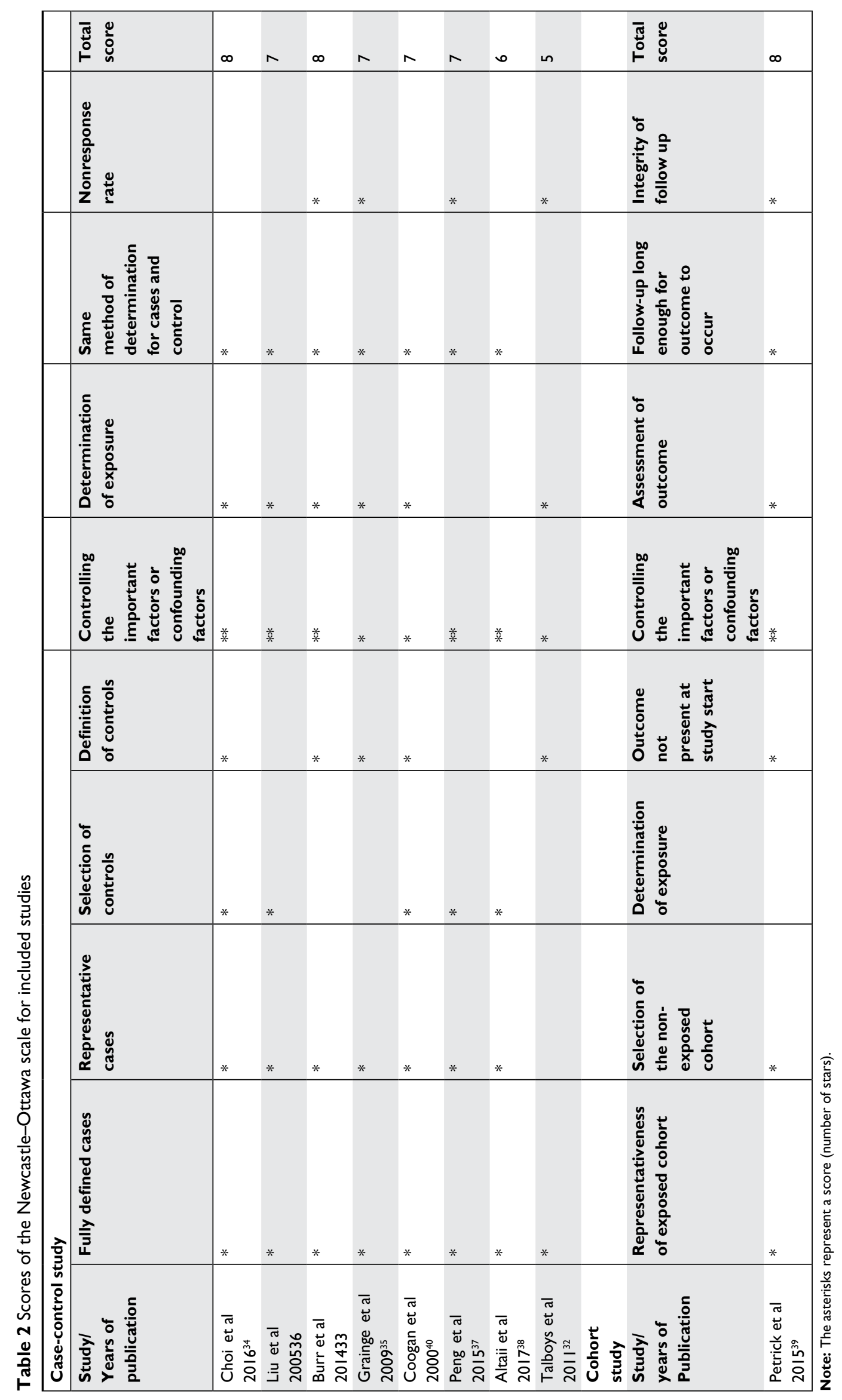


Study

ID
$\%$

ES $(95 \% \mathrm{Cl})$

$0.34(0.30,0.39)$

13.76

$0.94(0.70,1.27)$

11.76

$0.48(0.19,1.19) \quad 8.99$

$0.45(0.22,0.92) \quad 10.94$

$1.00(0.80,1.26) \quad 12.41$

$0.50(0.31,1.10) \quad 10.35$

$1.13(0.45,1.67) \quad 7.68$

$0.86(0.82,0.90) \quad 13.77$

$0.55(0.28,1.07) \quad 10.35$

$0.69(0.43,0.94) \quad 100.00$

Overall $(I-$ squared $=97.4 \%, p=0.000)$

NOTE: Weights are from random effects analysis

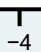

$-4$

Figure 2 Forest plot showing the relationship between aspirin and the risk of cholangiocarcinoma.

Notes: Points represent the risk estimates for each individual study. Horizontal lines represent $95 \% \mathrm{Cls}$, and diamonds represent the summary risk estimates with $95 \%$ Cls. Abbreviation: ES, effect size.

of malignancies, including colorectum, stomach, esophagus, breast, ovary, and lung. ${ }^{41-45}$ As far as we know, this is the first comprehensive meta-analysis exploring the association of aspirin use with $\mathrm{CCC}$ risk. We collected nine researches to explore the role of aspirin on CCC risk, which demonstrated that aspirin administration was related to a significant $31 \%$ decreased risk of CCC, especially in ICC.

Our finding of a decreased risk of CCC in patients taking aspirin has multiple possible explanations. Firstly, a previous study reported that overexpression of COX-2 might be a critical characteristic human $\mathrm{CCC},{ }^{46}$ indicating $\mathrm{COX}-2$ as potentially important targets relevant to chemoprevention or adjunct therapy of CCC. ${ }^{47,48}$ Thus, inhibition of COX-2 by aspirin may prevent CCC development through inhibition of inflammatory processes. Secondly, bile duct inflammation is a recognized cause of bile duct carcinogenesis. ${ }^{11}$ Therefore, suppression of COX-2 by aspirin might also inhibit CCC progression by suppressing inflammatory processes. ${ }^{16}$
The advantages of the study are as follows. To begin with, this is the first meta-analysis consisting of a large sample (12,535 CCC subjects and 92,97,450 healthy controls) in investigation of the role of aspirin in CCC risk, which might supply certain insight into the correlation of aspirin with CCC risk, and might be attractive in terms of CCC research. Moreover, further investigation concerning the mechanism of relationship of aspirin and CCC might give rise to novel therapeutic targets. Secondly, we further carried out subgroup and sensitivity analyses to identify the possible factors influencing the outcomes, which renders reliability of the present findings. Thirdly, the PubMed, EMBASE as well as Web of Science databases were comprehensively searched to collect possible researches in determining the factors affecting CCC risk. This systematic and comprehensive approach strengthened our findings. Additionally, the majority of enrolled researches harbored high quality in this meta-analysis. The above-described characteristics make our conclusions more reliable. 
Table 3 Subgroup and sensitivity analyses of the effect of aspirin and the risk of cholangiocarcinoma

\begin{tabular}{|c|c|c|c|c|}
\hline Subgroup & $\begin{array}{l}\text { No. of } \\
\text { studies }\end{array}$ & $\operatorname{RR}(95 \% \mathrm{Cl})$ & $I^{2}$ value(\%) & $P$-value \\
\hline All studies & 9 & $0.69(0.43,0.94)$ & 97.4 & 0.001 \\
\hline \multicolumn{5}{|l|}{ Subtype of cancer } \\
\hline ECC & 2 & $0.56(0.4 \mathrm{I}, 0.73)$ & 93.60 & 0.001 \\
\hline ICC & 3 & $0.33(0.26,0.39)$ & & 0.565 \\
\hline \multicolumn{5}{|l|}{ Geographic areas } \\
\hline West & 7 & $0.67(0.39,0.95)$ & 98 & 0.001 \\
\hline East & 2 & $0.78(0.43,1.42)$ & 61.7 & 0.106 \\
\hline \multicolumn{5}{|l|}{ Study deign } \\
\hline Cohort study & 1 & $0.94(0.70,1.27)$ & - & - \\
\hline Case-control study & 8 & $0.65(0.38,0.93)$ & 97.7 & 0.001 \\
\hline \multicolumn{5}{|l|}{ Adjustment for confounders } \\
\hline \multicolumn{5}{|l|}{ Cholangitis } \\
\hline Yes & 2 & $0.60(0.09,1.11)$ & 99.7 & 0.001 \\
\hline No & 7 & $0.73(0.52,0.94)$ & 57.2 & 0.029 \\
\hline \multicolumn{5}{|l|}{ Smoking } \\
\hline Yes & 5 & $0.72(0.39,1.04)$ & 98.7 & 0.001 \\
\hline No & 4 & $0.61(0.36,0.85)$ & 12.5 & 0.330 \\
\hline \multicolumn{5}{|l|}{ Alcohol intake } \\
\hline Yes & 3 & $0.85(0.59,1.12)$ & 57.8 & 0.094 \\
\hline No & 6 & $0.61(0.29,0.93)$ & 98.3 & 0.001 \\
\hline \multicolumn{5}{|l|}{ Sensitive analyses } \\
\hline High-quality studies & 7 & $0.62(0.32,0.92)$ & 89.2 & 0.001 \\
\hline \multicolumn{5}{|c|}{ Fixed-effects vs random-effects model method } \\
\hline Fixed-effects model & 9 & $0.64(0.6 \mathrm{I}, 0.67)$ & 97.4 & 0.001 \\
\hline Random-effects model & 9 & $0.69(0.43,0.94)$ & 97.4 & 0.001 \\
\hline
\end{tabular}

Abbreviations: ECC, extrahepatic cholangiocarcinoma; ICC, intrahepatic cholangiocarcinoma; RR, relative risk.

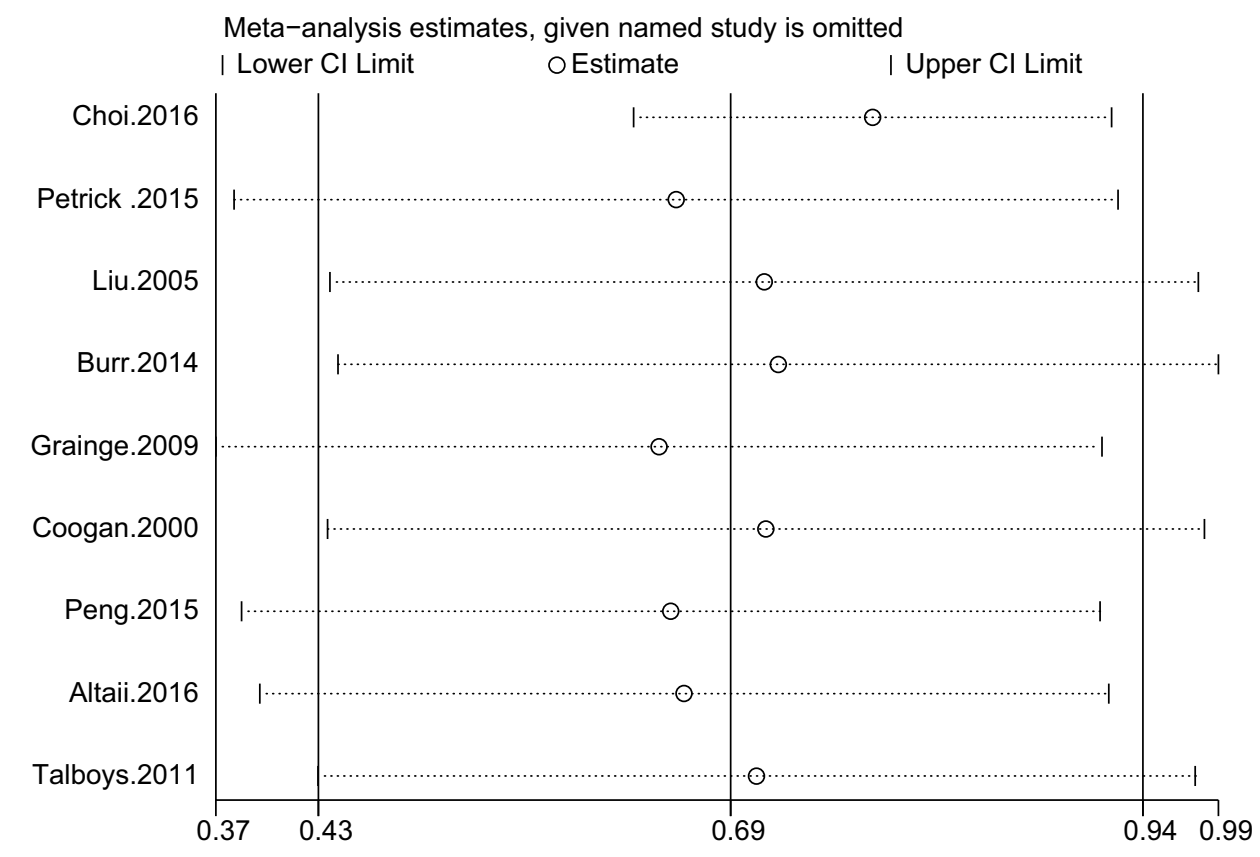

Figure 3 Sensitivity analysis of the association between aspirin and the risk of cholangiocarcinoma. 


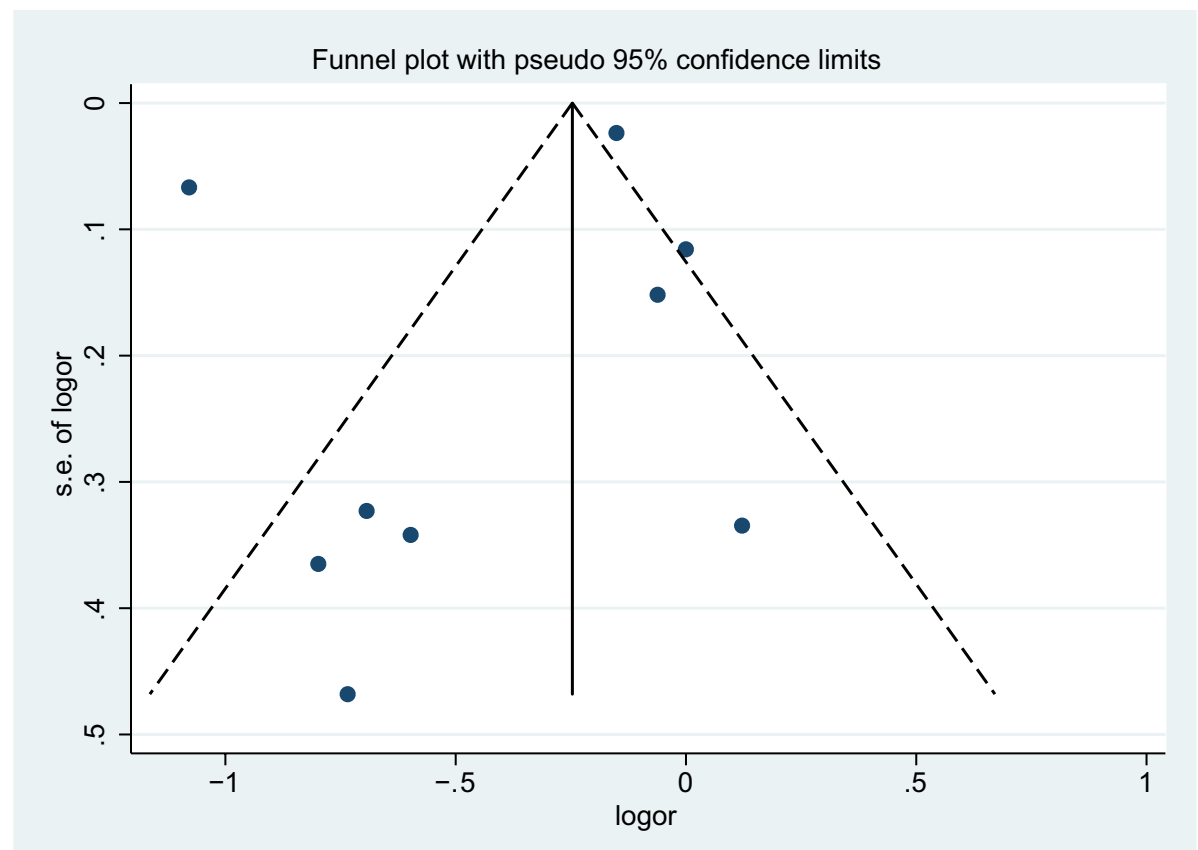

Figure 4 Funnel plot of studies included in the meta-analysis of the relationships between aspirin and the risk of cholangiocarcinoma. Abbreviations: logor, logodds ratio; s.e., standard error.

There exist certain shortcomings in the study. To begin with, the majority of the enrolled researches were case-control ones, thereby possibly leading to the generation of recall as well as selection biases. Besides, the current outcomes are subject to diagnostic bias. Those taking aspirin are prone to receive physical examination more frequently, which might result in more diagnoses than controls in general. Secondly, we did not search for unpublished studies or for original data. Besides, we did not take into account the possible interactions with other drugs due to a lack of relative data. Aspirin administration is often associated with other drugs use, such as statin and angiotensin converting enzyme inhibitors, which could have concealed a possible relationship with aspirin. ${ }^{49}$ Thirdly, we only investigated a correlation, which might be affected by confounding bias. The followings are well-defined risk factors for $\mathrm{CCC}$, including parasitic infections, bile duct cysts, hepatolithiasis as well as primary sclerosing cholangitis, ${ }^{9}$ which, however, have been adjusted in a few studies. Fourthly, we failed to conduct a meta-analysis concerning the roles of different duration or doses of aspirin due to the restricted number of enrolled researches. Nevertheless, three studies reported results on the impact of both the dose of aspirin and the duration of aspirin treatment. Two studies ${ }^{34,36}$ indicated that the impact of aspirin was dose dependent, with strong effect estimates in patients with $>3$ years of aspirin use in comparison with those harboring shorter use duration. Additionally, Choi et $\mathrm{al}^{34}$ reveal that lower dose of aspirin (81-162 mg/day) may be more beneficial for CCC, than high dose aspirins (>325 mg/day). Petrick et al, ${ }^{39}$ however, failed to discover a significantly different effect of aspirin when used for $>163 \mathrm{mg}$ or less. Finally, studies enrolled were significantly heterogeneous due to the differences in the study design, methods of measuring exposure, quality scores, and demographic characteristics inconsistency. In spite of inability to guarantee the source of heterogeneity, several sensitivity as well as subgroup analyses have been conducted to handle this issue.

In summary, our study indicated that aspirin administration was related to a significantly decreased CCC risk compared with those who never use aspirin. In the separate analysis of ICC and ECC, aspirin was suggested to be more strongly correlated with a decreased risk of ICC than that of ECC. More prospective and basic researches are warranted to confirm the correlation of aspirin with $\mathrm{CCC}$ risk as well as the potential mechanisms.

\section{Acknowledgments}

The study was funded by National key project research and development projects (S2016G9012), International Science and Technology Cooperation Projects (2015DFA30650), and 
the Capital Special Research Project for Clinical Application (Z151100004015170).

\section{Author contributions}

JPX conceived the study and wrote the manuscript. JPX and $\mathrm{HCH}$ searched database, reviewed studies, and selected date. WYX, YB, and JB performed statistical analyses. YYX, HTZ, and $\mathrm{XL}$ critically revised the article for essential intellectual content and administrative support. All authors made substantial contributions to conception and design, acquisition of data, or analysis and interpretation of data; took part in drafting the article or revising it critically for important intellectual content; gave final approval of the version to be published; and agree to be accountable for all aspects of the work.

\section{Disclosure}

The authors report no conflicts of interest in this work.

\section{References}

1. Olnes MJ, Erlich R. A review and update on cholangiocarcinoma. Oncology. 2004;66(3):167-179.

2. Patel T. Cholangiocarcinoma. Nat Clin Pract Gastroenterol Hepatol. 2006;3(1):33-42.

3. Tyson GL, El-Serag HB. Risk factors for cholangiocarcinoma. Hepatology. 2011;54(1):173-184.

4. Vauthey JN, Blumgart LH. Recent advances in the management of cholangiocarcinomas. Semin Liver Dis. 1994;14(2):109-114.

5. Shaib Y, El-Serag HB. The epidemiology of cholangiocarcinoma. Semin Liver Dis. 2004;24(2):115-125.

6. Taylor-Robinson SD, Toledano MB, Arora S, et al. Increase in mortality rates from intrahepatic cholangiocarcinoma in England and Wales 1968-1998. Gut. 2001;48(6):816-820.

7. Shaib YH, Davila JA, Mcglynn K, El-Serag HB. Rising incidence of intrahepatic cholangiocarcinoma in the United States: a true increase? J Hepatol. 2004;40(3):472-477.

8. Lepage C, Cottet V, Chauvenet M, et al. Trends in the incidence and management of biliary tract cancer: a French population-based study. J Hepatol. 2011;54(2):306-310.

9. Khan SA, Thomas HC, Davidson BR, Taylor-Robinson SD. Cholangiocarcinoma. Lancet. 2005;366(9493):1303-1314.

10. Cai H, Kong WT, Chen CB, et al. Cholelithiasis and the risk of intrahepatic cholangiocarcinoma: a meta-analysis of observational studies. BMC Cancer. 2015;15:831.

11. Palmer WC, Patel T. Are common factors involved in the pathogenesis of primary liver cancers? A meta-analysis of risk factors for intrahepatic cholangiocarcinoma. J Hepatol. 2012;57(1):69-76.

12. Welzel TM, Graubard BI, El-Serag HB, et al. Risk factors for intrahepatic and extrahepatic cholangiocarcinoma in the United States: a population-based case-control study. Clin Gastroenterol Hepatol. 2007;5(10):1221-1228.

13. Shaib YH, El-Serag HB, Nooka AK, et al. Risk factors for intrahepatic and extrahepatic cholangiocarcinoma: a hospital-based case-control study. Am J Gastroenterol. 2007;102(5):1016-1021.

14. Shaib YH, El-Serag HB, Davila JA, Morgan R, Mcglynn KA. Risk factors of intrahepatic cholangiocarcinoma in the United States: a case-control study. Gastroenterology. 2005;128(3):620-626.

15. Gupta A, Dixon E. Epidemiology and risk factors: intrahepatic cholangiocarcinoma. Hepatobiliary Surg Nutr. 2017;6(2):101-104.
16. Hayashi N, Yamamoto H, Hiraoka N, et al. Differential expression of cyclooxygenase-2 (COX-2) in human bile duct epithelial cells and bile duct neoplasm. Hepatology. 2001;34(4 Pt1):638-650.

17. Moher D, Liberati A, Tetzlaff J, Altman DG, PRISMA Group. Preferred reporting items for systematic reviews and meta-analyses: the PRISMA Statement. Open Med. 2009;3(3):e123-130.

18. Stroup DF, Berlin JA, Morton SC, et al. Meta-analysis of observational studies in epidemiology: a proposal for reporting. Meta-analysis Of Observational Studies in Epidemiology (MOOSE) group. JAMA. 2000;283(15):2008-2012.

19. Stang A. Critical evaluation of the Newcastle-Ottawa scale for the assessment of the quality of nonrandomized studies in meta-analyses. Eur J Epidemiol. 2010;25(9):603-605.

20. Zhang YP, Li WQ, Sun YL, Zhu RT, Wang WJ. Systematic review with meta-analysis: coffee consumption and the risk of gallstone disease. Aliment Pharmacol Ther. 2015;42(6):637-648.

21. DerSimonian R, Laird N. Meta-analysis in clinical trials. Control Clin Trials. 1986;7(3):177-188.

22. Higgins JP, Thompson SG. Quantifying heterogeneity in a meta-analysis. Stat Med. 2002;21(11):1539-1558.

23. Begg CB, Mazumdar M. Operating characteristics of a rank correlation test for publication bias. Biometrics. 1994;50(4):1088-1101.

24. Egger M, Davey Smith G, Schneider M, Minder C. Bias in meta-analysis detected by a simple, graphical test. $\mathrm{Br}$ Med $\mathrm{J}$. 1997;315(7109):629-634.

25. Stuck AE, Rubenstein LZ, Wieland D. Bias in meta-analysis detected by a simple, graphical test. Asymmetry detected in funnel plot was probably due to true heterogeneity. $\mathrm{Br}$ Med $\mathrm{J}$. 1998;316(7129):469-469.

26. Xiong J, Lin J, Wang A, et al. Tea consumption and the risk of biliary tract cancer: a systematic review and dose-response meta-analysis of observational studies. Oncotarget. 2017;8(24):39649-39657.

27. Long-term use of aspirin linked to reduced risk of developing bile duct cancer. Nurs Stand. 2016;30(38):15.

28. Friis S, Poulsen AH, Johnsen SP, et al. Cancer risk among statin users: a population-based cohort study. Int J Cancer. 2005;114(4):643-647.

29. Cichoz-Lach H, Celiński K. Can nonsteroidal anti-inflammatory drugs favourably affect the alimentary canal? Ann Univ Mariae Curie Sklodowska Med. 2002;57(2):399-402.

30. Morgan G. Beneficial effects of NSAIDs in the gastrointestinal tract. Eur J Gastroenterol Hepatol. 1999;11(4):393-400.

31. Sakoda LC, Gao YT, Chen BE, et al. Prostaglandin-endoperoxide synthase 2 (PTGS2) gene polymorphisms and risk of biliary tract cancer and gallstones: a population-based study in Shanghai, China. Carcinogenesis. 2006;27(6):1251-1256.

32. Talboys RJ, Burr N, Savva S, et al. The role of non-steroidal antiinflammatory drugs and statins in the aetiology of cholangiocarcinoma: preliminary results from a case control study in two UK centres. Gastroenterology. 2011;140(5):S-595.

33. Burr NE, Talboys RJ, Savva S, et al. Aspirin may prevent cholangiocarcinoma: a case-control study from the United kingdom. Dig Dis Sci. 2014;59(7):1567-1572.

34. Choi J, Ghoz HM, Peeraphatdit T, et al. Aspirin use and the risk of cholangiocarcinoma. Hepatology. 2016;64(3):785-796.

35. Grainge MJ, West J, Solaymani-Dodaran M, Aithal GP, Card TR. The antecedents of biliary cancer: a primary care case-control study in the United Kingdom. Br J Cancer. 2009;100(1):178-180.

36. Liu E, Sakoda LC, Gao YT, et al. Aspirin use and risk of biliary tract cancer: a population-based study in Shanghai, China. Cancer Epidemiol Biomarkers Prev. 2005;14(5):1315-1318.

37. Peng YC, Lin CL, Hsu WY, et al. Statins are associated with a reduced risk of cholangiocarcinoma: a population-based case-control study. $\mathrm{Br}$ J Clin Pharmacol. 2015;80(4):755-761.

38. Altaii H, Al-Kindi SG, Oliveira GH, Yaqoob Z, Romero-Marrero C. Aspirin use and risk of cholangiocarcinoma: external validation with big data. Hepatology. 2017;65(4):1421-1422. 
39. Petrick JL, Sahasrabuddhe VV, Chan AT, et al. NSAID use and risk of hepatocellular carcinoma and intrahepatic cholangiocarcinoma: the liver cancer pooling project. Cancer Prev Res. 2015;8(12):1156-1162.

40. Coogan PF, Rosenberg L, Palmer JR, et al. Nonsteroidal anti-inflammatory drugs and risk of digestive cancers at sites other than the large bowel. Cancer Epidemiol Biomarkers Prev. 2000;9(1):119-123.

41. Flossmann E, Rothwell PM. Effect of aspirin on long-term risk of colorectal cancer: consistent evidence from randomised and observational studies. The Lancet. 2007;369(9573):1603-1613.

42. Hochmuth F, Jochem M, Schlattmann P. Meta-analysis of aspirin use and risk of lung cancer shows notable results. Eur J Cancer Prev. 2016;25(4):259-268.

43. Cao Y, Nishihara R, Wu K, et al. Population-wide impact of long-term use of aspirin and the risk for cancer. JAMA Oncol. 2016;2(6):762-769.

44. Tang L, Hu H, Liu H, Jian C, Wang H, Huang J. Association of nonsteroidal anti-inflammatory drugs and aspirin use and the risk of head and neck cancers: a meta-analysis of observational studies. Oncotarget. 2016;7(40):65196-65207.
45. Huang XZ, Chen Y, Wu J, et al. Aspirin and non-steroidal anti-inflammatory drugs use reduce gastric cancer risk: a dose-response meta-analysis. Oncotarget. 2017;8(3):4781-4795.

46. Endo K, Yoon BI, Pairojkul C, Demetris AJ, Sirica AE. ERBB-2 overexpression and cyclooxygenase-2 up-regulation in human cholangiocarcinoma and risk conditions. Hepatology. 2002;36(2):439-450.

47. Sirica AE, Lai GH, Endo K, Zhang Z, Yoon BI. Cyclooxygenase-2 and ERBB-2 in cholangiocarcinoma: potential therapeutic targets. Semin Liver Dis. 2002;22(3):303-314.

48. Sirica AE, Lai GH, Zhang Z. Biliary cancer growth factor pathways, cyclo-oxygenase-2 and potential therapeutic strategies. J Gastroenterol Hepatol. 2001;16(4):363-372.

49. Takkouche B, Etminan M, Caamaño F, Rochon PA. Interaction between aspirin and ACE Inhibitors: resolving discrepancies using a metaanalysis. Drug Saf. 2002;25(5):373-378.
Cancer Management and Research

\section{Publish your work in this journal}

Cancer Management and Research is an international, peer-reviewed open access journal focusing on cancer research and the optimal use of preventative and integrated treatment interventions to achieve improved outcomes, enhanced survival and quality of life for the cancer patient. The manuscript management system is completely online and includes
Dovepress

a very quick and fair peer-review system, which is all easy to use. Visit http://www.dovepress.com/testimonials.php to read real quotes from published authors. 